\title{
Stefan Zweig y Kurt Tucholsky: dos voces pacifistas a principios del siglo pasado
}

\author{
SusAnNe SCHUlze-Boysen \\ Escuela de Lenguas Modernas \\ Universidad de Costa Rica
}

\begin{abstract}
Resumen
En este escrito se trata de ilustrar, con base en dos autores, uno austriaco y uno alemán, que a finales del siglo antepasado y principios del siglo anterior hubo un movimiento antimilitarista y paneuropeo de pensadores, tanto en Alemania como en Austria. Para corroborar esta afirmación, se analizan por su contenido algunas obras de dichos autores.
\end{abstract}

Palabras claves: paz, guerra, tolerancia, agresión, fanatismo, incomprensión, humanismo, Europa

\section{Abstract}

At the end of the $19^{\text {th }}$ and the beginning of the $20^{\text {th }}$ century there was a pacifist European movement, and based on some productions of an Austrian and a German writer, this paper is aiming to corroborate this affirmation.

Key words: peace, war, tolerance, aggression, fanaticism, incomprehension, humanism, Europe

\section{Introducción}

$\mathrm{E}$ l siglo XIX fue un periodo de violencia y guerras en Europa, como lo fueron también los siglos anteriores y sobre todo el siglo siguiente. La guerra franco-prusiana (junio 1870-mayo 1871) fue la primera guerra moderna industrializada, con muchas víctimas, sobre todo en la batalla de Sedan (Francia). 
En el año del centenario del comienzo de la Gran Guerra (Primera Guerra Mundial), se presta mucha atención al estudio de esta época, sobre todo con referencia a la situación actual, pues ha habido cambios y sin embargo nada parece haber mejorado. La idea común es que alemanes y austriacos son dos pueblos muy bélicos y que las tropas se colocaban en el frente de batalla con entusiasmo y alegría. Pero no fue así, en realidad, el pueblo no tenía ganas de pelear, matar ni, por ende, morir.

Para ellos la guerra fue provocada por los otros países y no concebían la idea de que sus reyes y emperadores, a quienes percibían como padres, hubieran acudido a una guerra si no fuese necesario; de ahí quizás que lo hayan hecho con mayor entusiasmo pues pensaban que esta guerra no duraría mucho tiempo, contrario a la Segunda Guerra Mundial adonde fueron desencantados, sin ilusiones.

Muchos artistas y escritores europeos de la época persiguieron la idea de un entendimiento paneuropeo y una paz duradera. Dos representantes de este movimiento fueron Stefan Zweig, un autor originario de Viena, y Kurt Tucholsky, escritor proveniente de Berlín.

Stefan Zweig goza de fama mundial, sus obras fueron traducidas a 50 lenguas, mientras que Tucholsky es más que todo un escritor conocido en Alemania, pues se dirigió a un público germano y usó a menudo dialectos, más que todo el berlinés.

En los siguientes apartados se ahondará en estos dos los autores y se realizará un comentario sobre algunos de sus textos, que se oponen a la violencia y las guerras e instan, en cambio, a una convivencia pacífica.

\section{Stefan Zweig}

Stefan Zweig nació en Viena en 1881 y durante su vida tuvo varias nacionalidades: hasta 1918 perteneció al Impero Austrohúngaro, después fue austriaco hasta que se exilió a Inglaterra en 1938 y se le otorgó la nacionalidad británica, la cual mantuvo hasta su suicidio en Brasil en 1942.

Una de las causas de su suicidio fue la imposibilidad de publicar en Alemania y Austria, públicos meta del escritor por ser hablantes de su lengua materna; además, estaba la aparente victoria del nazismo y su correspondiente expansión por todo el globo.

Su padre fue un acaudalado fabricante textil y su familia, judía. Comenzó a escribir desde el colegio y durante su vida produjo un vastísimo volumen de obras, sobre todo novelas, relatos y biografías. Durante la Primera Guerra Mundial, trabajó por un periodo en la Oficina de Guerra, ya que no era apto para el frente de batalla y apenas le fue posible, se exilió en Zurich hasta el final de la guerra.

Zweig es más que todo conocido por los catorce relatos compilados en $M o$ mentos estelares de la humanidad (1929), en los que narra los momentos decisivos en la historia del mundo, los cuales fueron provocados, según él, por pequeños detalles que determinaron grandes acontecimientos. Uno de los relatos en este libro, Die Weltminute von Waterloo (El minuto mundial de Waterloo), cuenta 
de la batalla, de cómo Napoleón divide sus tropas en dos, una parte para enfrentarse con Wellington y otro tercio de sus hombres para seguir a los soldados prusianos en su retiro y evitar su unión con los ingleses. El mariscal francés es fiel y sigue los mandatos de su comandante y cuando oye el ruido de los cañones, no se mueve hasta esperar nuevas órdenes. Como falló en la orden de perseguir a los prusianos, quienes se unen con las tropas de Wellington, el resultado fue la derrota de Napoleón. Otra obra muy conocida es su Novela de ajedrez, publicada en 1941 en Brasil. Esta trata de un preso de la Gestapo en Viena quien encuentra en la bolsa del abrigo de uno de sus torturadores un libro que narra crónicas de los partidos de los grandes campeones de ajedrez y se aprende todas las partidas para no enloquecer.

Su amor por la libertad y la paz también se perciben en las biografías de Erasmo de Rotterdam (1934) y en Castello contra Calvino. Su obra póstuma El mundo de ayer - recuerdos de un europeo (1944) es una autobiografía que describe sobre todo la vida a finales del siglo XIX e inicios del siglo XX en el imperio austrohúngaro y en el resto de Europa, todo de una manera extraordinariamente narrada.

\section{El mundo de ayer}

En su autobiografía, Zweig describe su infancia y feliz adolescencia en Viena, se burla de la vita sexualis de la época victoriana y es esta obra el primer encuentro con la hipocresía y mentira del mundo adulto de autoridad. El tema de la sexualidad era considerado tabú en la sociedad burguesa y aristocrática, sobre todo para el sexo femenino.

Sin embargo, la juventud tenía más libertad civil, no tenía obligaciones militares ni el Arbeitsdienst (servicio de trabajo obligatorio bajo el régimen nazi). Podían concentrarse en sus artes e inclinaciones mentales y vivir la existencia privada sin la preocupación de sentirse vigilados. Se vivía de manera cosmopolita, viajando sin pasaporte o permiso especial, nadie preguntaba sobre intenciones, país de origen, raza ni religión.

Cuando entró en la Universidad de Viena, se encontró con el uso de la brutalidad que se manifestaba entre los Burschenschaften (grupos de estudiantes comparables con las fraternidades en los Estados Unidos) que gozaban de privilegios, como poder medirse a duelo, tomar alcohol hasta caerse y pasar por las calles haciendo mucho ruido en las noches. Él trató de evitar confrontarse con estas hordas, pues la libertad individual para él tenía prioridad; además, consideró la agresión y el servilismo como lo más horrible y peligroso del espíritu alemán. Asimismo, como puede pasar hoy en día, la pertenencia a un cierto grupo durante el estudio permitía un fácil acceso al ejercicio de la profesión.

Zweig comenzó a escribir en un periódico cuando era muy joven, el Neue Freie Presse; en el folletín aparecieron sus poemas y novelas, cuando tenía apenas 19 años. Sin embargo, sintió el deseo de ir a Berlín, una ciudad que apenas estaba empezando a ganar una posición en la cultura mundial. 
Solo desde 1870, año en que se formó el impero alemán y bajo el protectorado del emperador Guillermo, la ciudad creció con ambiciones de sobresalir, atrayendo a talentos jóvenes. Con respecto a su vida en Viena, Zweig se sintió más libre e inspirado. Su percepción sobre las diferencias en el estilo de vida de Berlín comparado con el de las ciudades como Viena y París se define en la parsimonia prusiana, la falta de elegancia, el café y la comida sin gusto. Reinaba la higiene y el orden estricto. En Viena, la dueña de su departamento no siempre tenía todo limpio, pero con mucho entusiasmo cumplía con los favores pedidos. La señora berlinesa, en cambio, ponía todo en la cuenta al final del mes, cada pequeño servicio.

En Berlín descubrió mucha libertad y creatividad, con artistas llegados de todas partes y con raíces muy distintas. Quiso aprender y conocer antes de producir; viajó primero a Bélgica, con la intención de conocer a Emile Verhaerens, el poeta que todavía no era famoso, pero muy amado por Zweig, quien lo llama un Walt Whitman europeo. Verhaerens pudo expresar su entusiasmo por el mundo moderno y su aprecio de los diferentes pueblos europeos. Dicho optimismo fue característico de toda la generación fin de siècle. Zweig dedicó dos años a la traducción de sus obras y a su biografía.

Con un doctorado en filosofía, el escritor vienés se dirige a París, esta ciudad capaz de hacer feliz a sus visitantes jóvenes, con su entrega generosa, una ciudad ingenua y serena, que ofrece su ejemplo para ser libre y al mismo tiempo creativo. A principios del siglo XX, Europa se alegró con sus colores caleidoscópicos. Y entonces París fue la ciudad más despreocupada, gracias a la belleza de sus formas, su clima benigno, su riqueza y su tradición. La libertad de vivir a su gusto llenaba el aire, las diferencias sociales se vivían a nivel horizontal, no había jerarquía, a diferencia de Berlín donde la sociedad estaba bien estructurada. En este ambiente prolífero, Zweig pudo desplegar su libertad de pensamiento, siempre estimulado por sus amigos.

Rainer Maria Rilke estuvo más presente en París para Zweig que en otros lugares y él se pregunta en el texto si nunca más van a volver los poetas dedicados exclusivamente a su lírica, sin desear reconocimientos ni honores, solamente atentos a completar la estrofa, cada línea llena de música, colores y cuadros.

Después de su estadía en Londres decidió viajar más lejos, primero a India y después a Estados Unidos. Durante su viaje en barco a India, conoció a Karl Haushofer, el agregado militar alemán en Tokio. Admiró mucho las extraordinarias calidades y la disciplina de este oficial del cuartel general del ejército alemán, muy culto y educado. Según él, todo buen científico de la ciencia debería manejar el conocimiento de todas las otras áreas científicas. Haushofer promocionó la reconstrucción sistemática y generosa del poder alemán e identificó el "Lebensraum" como la energía relativa de una época que se distribuye cíclicamente y coloca en una nación la prominencia en todos los ámbitos (arte, ciencia, cultura, economía). La idea era desarrollar el estudio de las calidades individuales de los pueblos y de un mecanismo instructivo de naturaleza científica. Hoy en día, la importancia de este pensador universal se asocia sobre todo con la interpretación nazi, al definir el "Lebensraum" en un sentido limitado y brutal, en el que ellos eran los únicos destinados a la grandeza desde siempre. Muchas veces 
los nacionalsocialistas se aprovecharon de ideologías ajenas para justificar sus ambiciones de poder. "Heute gehört uns Deutschland, morgen die ganze Welt" (Hoy nos pertenece Alemania, mañana el mundo entero) fue uno de sus slogans.

Siempre en su autobiografía, específicamente en el capítulo "Glanz und Schatten über Europa" (Luminosidad y sombra sobre Europa), describe cómo en los primeros diez años del nuevo siglo hubo mucha esperanza en una Europa unida, que se creía con optimismo y confianza, después de 40 años sin guerra.

Con la paz y la industrialización, los nuevos inventos y descubrimientos, todos los países del Viejo Continente se expandieron económica, social y culturalmente. Las ciudades crecieron y se embellecieron, se crearon nuevos teatros, bibliotecas y museos, los baños y teléfonos entraron en las casas de la pequeña burguesía. El proletariado pudo, con sus horas de trabajo reducidas, participar del ocio. La dirección se percibía solo hacia adelante; la misma humanidad mejoró con el deporte y una mejor nutrición; la gente pasaba más tiempo al aire libre.

La liberación femenina logró sus primeros frutos, la juventud tuvo sus primeras premiaciones, el ambiente se llenó de alegría y despreocupación. Y los nuevos inventos no se identificaron con la nacionalidad del inventor; todos los europeos seguían las pruebas del primer Zeppelin (dirigible) y se entusiasmaron por el primer vuelo sobre el Canal de la Mancha.

El pensamiento de Zweig concluye que el progreso fue demasiado rápido y que el poder puede llevar a las personas y a los estados al abuso. La expansión no quiso cerrarse, la cooperación se convirtió en competencia. El inicio de la Gran Guerra pudo derivarse de esta abundancia de poder, del dinamismo acumulado durante los cuarenta años de paz. Cada estado se estimó más fuerte, pero todos mantenían su optimismo.

Los intelectuales, por su parte, no querían enfrentarse conforme se agudizó la situación política, pensando poder realizar de manera europea el ideal de comprensión pacífica y fraternidad espiritual, y sobrepasar las divisiones geográficas, políticas e idiomáticas.

Al contemplar la historia en su biografía, Zweig admite que los jóvenes en general, y los jóvenes intelectuales en particular, no quisieron darse cuenta del aumento de la tensión, estaban confiados en que los políticos iban a evitar el desastre. Entre los jóvenes intelectuales, existía amistad y respeto; Zweig les tradujo textos a varios autores y los acompañó en giras por Alemania y Austria, pero no tuvo mucha influencia en las esferas de mando.

Sin embargo, el escritor y musicólogo humanista Romain Rolland representó mejor el concepto de la hermandad entre las naciones europeas, pues con un enfoque moral reconoció de manera amable y sincera las particularidades de los distintos países y creyó en la misión unificadora de las artes. Escribió la primera novela europea que llamaba a la fraternidad, con los diez volúmenes de Jean-Christophe un roman fleuve, basado parcialmente en la vida de Beethoven. Hablando con Zweig en 1913, lo sensibilizó a reaccionar contra una posible guerra europea. En Austria, especialmente, se percibía la hecatombe próxima de la monarquía milenaria. Las naciones pertenecientes al imperio y los vecinos ya estaban dispuestos a desmembrarlo. 
Otra conocida muy influyente fue Berta von Suttner, llamada Cassandra, por su actividad pacifista, quien escribió la novela Die Waffen nieder (Bajan las armas), un éxito mundial. Ella instigó a los jóvenes para unirse a protestar contra la violencia que venía en camino.

De nuevo en Francia, Zweig tuvo una experiencia alarmante: andaba en el cine de la pequeña ciudad provincial de Tours y como era de costumbre, antes de la película se proyectaban las noticias del mundo. El Kaiser Wilhelm visitó al Kaiser Franz Josef en Viena; primero se vio al Kaiser austriaco, viejo y cojo con su barba blanca y la gente se reía de simpatía. Pero cuando bajó del tren el Kaiser alemán con su bigote encurvado hacia arriba, el público comenzó a gritar y a patalear. La propaganda del odio ya se había extendido hasta la provincia para provocar esta histeria de masas.

En el verano de 1914, Zweig se había propuesto primero trabajar sobre Dostoievski para completar su libro Tres maestros, y después, visitar a Verhaeren, pero el 28 de junio se disparó el conflicto en Sarajevo y el mundo seguro y racional cayó en mil pedazos, pero no inmediatamente.

El verano 1914 fue extraordinariamente bello, la gente disfrutaba del sol y de la naturaleza. No obstante, ni el heredero al trono ni su esposa gozaban de mucha simpatía y menos de cariño. Nadie imaginaba que este hecho hubiera podido originar la guerra; se le consideraba como los conflictos anteriores que se resolvieron en el último momento de manera diplomática antes de estallar en guerra.

Zweig con su autobiografía nos muestra la visión de una época en transición, llena de ilusiones, que no se imaginaba la magnitud de la guerra que habría de cambiar sus vidas y la de toda la nación. En la siguiente novela se abarcará la óptica de quien participa en la guerra.

\section{Der Zwang}

La novela Der Zwang (La coerción) habla de un pintor austriaco, Fernando, quien vive felizmente con su esposa en una casita sobre el lago de Zurich en Suiza durante la guerra. Tuvo la suerte de no haber pasado el examen médico para combatir en la guerra, y por influencia de conocidos, le dieron permiso para viajar al país vecino neutral. Pasan los días tranquilos en un paisaje de encanto, sus nervios ya se habían calmado después de haber visto escenas muy tristes, como las mujeres sufriendo de frío al amanecer, sentadas en el mercado con sus sacos de patatas vacías. Ahora trabaja bien y trata de dedicarse completamente a su arte, cuando siente de nuevo una sensación de miedo. Llega el cartero trepando la colina con un sobre sellado "oficial". Lo que teme desde hace tiempo se manifiesta: desde su cuartel en Austria lo llaman para exponerse a la segunda revisión médica.

Primero, considera no abrir el sobre, que ya ha anticipado. Ocho meses antes lo habían examinado como si fuera un caballo. Sintió la humillación y la esclavitud dominante en Europa. Su alma sufrió por la compasión y por la repugnancia 
contra su misma persona, por su incapacidad de expresar su cólera. Ahora la patria es solamente prisión y coerción.

Tiene en sus manos el sobre y piensa en la posibilidad de no abrirlo, de desgarrarlo junto con su contenido, nadie puede exigirle leer lo que dice, él es un hombre libre. Pero los músculos no le obedecen. Abre el sobre y lee que debe presentarse al comando regional y recoger sus papeles militares en el consulado.

Cuando no puede comer, su esposa se da cuenta y sabe lo que pasó. Muchas veces habían hablado de esta posibilidad y de cómo él debía reaccionar. Ella le pregunta si va a ir al consulado y él le contesta que sí, que es su deber. Paula argumenta que es solamente un papel, que no pasa nada, él se encuentra en un país donde es libre, que quien escribió estas líneas, la máquina matadora de hombres, no tiene ningún poder sobre un hombre libre.

Fernando le replica que no quiere ir, que va contra su voluntad. Lo terrible del poder es que extingue la voluntad individual, solo se puede obedecer. Él es perfectamente consciente de que su única obligación es ser hombre y trabajar, que el Estado no tiene ningún derecho a llamarlo para matar a otros hombres. Sin embargo, siente su límite, la coerción de no romper la cadena que estrangula a veinte millones de hombres. Los que lo llaman son preparados, son fuertes, son organizados y él es débil de voluntad y de nervios. No puede luchar contra una máquina sin alma, corazón ni razón.

Paula contrapone que ella luchará por él, que encontrará un médico para certificar su enfermedad nerviosa. Estas autoridades no tienen más poder de lo que el mundo les da. Hay que resistir con la propia humanidad, con la voluntad de un ser libre. Fernando admite que antes de recibir la orden podía prepararse a contestar y rechazar el llamado. Pero estas palabras fueron mentiras, tiembla de miedo. Reconoce que su esposa tiene toda la razón y que es un infame por ir, un hombre despreciable.

Paula busca calmarlo, haciéndole ver la belleza del atardecer, la tranquilidad del campesino arando su tierra y que las leyes de este país también valen para él. Trata de convencerlo de que no vaya mañana al consulado, que deje pasar unos días, esperando calmarse. Fernando solamente lo mira con los ojos vacíos, perdidos, apáticos. Se da un empujón y acepta que puede esperar ocho días.

Sin embargo, en la mañana siguiente, al amanecer, toma su sombrero y su abrigo y sale, corre a la estación a tomar el tren para Zurich. Está tan agotado que no puede leer el periódico dejado en el compartimiento y en la ciudad se echa en un coche como un suicida se echa en el río, con dirección hacia el consulado. Llega y lo encuentra cerrado. Toca el timbre y llega un sirviente con un paño en la mano, informándole que las horas de atención son de las diez hasta las doce. Con mucha vergüenza, Fernando se da cuenta de que son apenas las siete pasadas. Y la escena preparada lo está desvaneciendo. La intención era aparecer controlado y soberano, manteniendo la posición de que le es imposible dejar su trabajo ahora, que está alistando una exhibición. También se imagina la parte final, donde aunque el encargado dijera que no es posible rechazar la orden militar, él se quede firme con la postergación de tres semanas. 
Para pasar el tiempo, va a un bar a tomar unos coñacs, enseguida va al peluquero para rasurarse y peinarse, después se compra unos guantes y un bastón. A la hora de apertura lo mandan a la sala de espera, donde ya hay otros solicitantes. Fernando se irrita al escuchar la conversación y cuanto más pasa el tiempo, más se desvanece su energía. Se siente preso, sin resistencia.

El secretario lo recibe y sabe inmediatamente de que se trata, ya tiene todo listo. Le recomienda esperar unos días para terminar su obra y Fernando solamente logra preguntar si no necesita además un pasaporte. Al salir de la oficina casi se desmaya, no encuentra la puerta correcta y cuando el secretario le abre la puerta se lo agradece. Bajando las escaleras siente de nuevo mucha vergüenza, pero ya no es él mismo quien camina: el poder sin compasión lo oprime, como al resto del mundo.

Cuando vuelve a su casa, su esposa le explica que aceptar esta esclavitud contra la propia conciencia y convencimiento es ayudar a los criminales. Diez hombres monstruosos tienen el mundo en sumisión, pero un solo hombre que se niega puede destruir el poder. Ella le permite combatir por sus ideas, no por la locura de otros. Él debe decidir: se queda con ella o la pierde para siempre.

A solas en la tarde, se encuentra empacando el bulto. Sus manos hacen todo sin voluntad. Paula lo mira con desprecio y sale. Solamente el perro le muestra cariño. La mañana siguiente está inspirado y decide no viajar. Saca del bolsillo el papel que lo llama; al tenerlo en la mano su fuerza disminuye rápidamente y se agita. Toma su bulto y se precipita. ¿Y a quién encuentra delante de la barrera próxima al andén? Es Paula quien insiste, quien no lo deja ir a su perdición, lo quiere libre, no como Kanonenfutter (alimento para cañones). Ya se oyen las señales de la llegada del tren, Fernando quiere recoger su bulto caído, pero Paula lo recoge más rápidamente y luchan hasta que se escucha el silbato del tren. Fernando deja el bulto y corre, se esconde en el tren .

En la frontera suiza se baja y contempla la realidad, en este lado puede vivir, respirar, hablar, actuar según su propia voluntad. A ochocientos pasos, por el otro lado del puente, la voluntad se sale del cuerpo, se debe obedecer a personas desconocidas y hay que acuchillar en el pecho a desconocidos. Esperando y pensando sobre el puente como frontera entre la zona de paz y la zona de guerra, su voluntad comienza a recuperarse y se propone tomar el tren que lo llevó hasta la frontera de vuelta hacia Suiza.

En ese momento se oye el tren que lo llevará a su cuartel. De repente, una multitud de mujeres y hombres sale de las salas. Se escucha La Marseillaise, el tren para y bajan soldados franceses mutilados. Es un tren con presos de intercambio quienes salen de la locura de la guerra. El andén se llena de alegría, aun con soldados sin brazos o piernas, quemados, los restos de una juventud precozmente envejecida. Fernando se acerca a una camilla aislada, le pone al enfermo el brazo destrozado en el pecho. El enfermo abre los ojos y le sonríe agradecido.

Es ahí cuando ve la situación en su total claridad. ¿Se debe mutilar a las personas, mirarlas a sus ojos con odio, participar de su propia voluntad en este gran crimen? La máquina se quiebra en su pecho, crece su sentido de la libertad, feliz y grande. Nunca va a participar en esta matanza, rompe el papel y vuelve a su pequeña casa en el campo. 
En esta novela se expresa el conflicto entre la voluntad individual y el instinto humano de reunirse al rebaño, al llamado "sentido del deber", en el cual se deja la responsabilidad en la toma de decisiones a las autoridades superiores y finalmente se asume el sentido de culpa en caso de no agruparse, de no cumplir con su "deber".

\section{Erasmo de Rotterdam}

Este personaje humanista, grande y famoso del siglo XVI, hoy está casi olvidado, superado por los reformadores de entonces más fuertes y vehementes. Él vivió para su trabajo, escribiendo en un idioma transnacional que hoy se habla muy poco, el latín. Su carácter no se pudo catalogar, lleno de medias luces y contradicciones. Su gran mérito está por así decirlo, medio sepultado, a pesar de ser entre todos los escribanos de Occidente el primer europeo consciente, el primer luchador por la paz, el abogado más genial del ideal humanístico. Además, el hecho de que fuera derrotado en su búsqueda de una forma más justa y tolerante de nuestro mundo mental, lo hace más admirable a nuestros ojos. Amó la poesía, la filosofía, los libros, las obras de arte, los idiomas y los pueblos, sin hacer distinción. Y no soportó el fanatismo. Según él, todos los conflictos entre personas y pueblos se pueden solucionar sin violencia, mediante un acuerdo. Luchó contra el fanatismo religioso, nacional o ideológico. No pretendía la aceptación de sus ideas, pero en este mismo sentido no permitía que otros lo obligaran a un credo religioso y político. Con su espíritu independiente consideró la imposición de una visión personal como una reducción de la multitud divina en el mundo. En su Elogio de la locura clasificó y caricaturizó mil formas de la "stultitia". Como persona justa y sin prejuicios, entendió y compadeció a sus enemigos más enconados.

Su misión fue la convivencia armoniosa de los contrastes de una manera humanitaria. Sobre todo la guerra, para él, fue la forma más ruda y violenta de la confrontación de discordancias, no aceptable para una humanidad moralmente comprometida. Erasmo tenía el don poco común de atenuar los contrastes por indulgencia y aclarar lo impreciso para que no existiera confusión.

Para él, eran posibles los puntos de encuentro de visiones en apariencia irreconciliables, de esta manera no existía ningún contraste moral entre Jesús y Sócrates, entre la doctrina cristiana y la sabiduría de la Antigüedad. Sin residencia en un país concreto y al mismo tiempo presente en todos, fue el primer cosmopolita europeo, quien no admitía la superioridad de una nación sobre otras. Su meta fue elevar la civilización mediante la unión de los literatos, quienes pensaban en el bienestar de toda la humanidad.

Zweig se pregunta, al mismo tiempo, cómo es posible que este triunfo de los ideales y de la comprensión recíproca no pudo durar en un mundo que ya conocía la insensatez de todas las hostilidades. Nunca un ideal que persigue el bienestar común satisface a las masas populares, el hombre promedio siente lo mismo, tanto el odio como el amor y el egoísmo, solo quiere aprovecharse rápidamente de cada nueva idea. A la masa le sirve más lo concreto, lo producido, que 
el pensamiento abstracto y en política es más fácil ganar con argumentos antagónicos que con los de una unión ideal. Existe siempre pasión por lo irracional que se contrapone a quienes persiguen el entendimiento mundial.

La desgracia en la vida de Erasmo fue vivir en un momento muy convulso de pasiones religiosas y nacionales. En los siglos anteriores, las guerras tocaban solamente una parte de los pueblos, algunas provincias y el literato podía abstraerse en sus cavilaciones. Pero en la reforma religiosa de entonces hay tal tensión entre las partes discordantes que cada país, ciudad y familia la siente. Hay histeria colectiva, reina el fanatismo. El literato no puede apartarse, por tanto, a una observación objetiva, las partes lo reclaman, tiene un deber.

Lutero fue el primer reformador alemán que trató de renovar la iglesia católica mediante el razonamiento. Pero el hombre contemplativo se encuentra frente al hombre de acción: Martín Lutero, el revolucionario. Con un duro golpe, el doctor Lutero arruina lo que Erasmo quiso unir solamente con su pluma. El mundo europeo cristiano se divide: católicos contra protestantes, norte contra sur, alemanes contra romanos. Los alemanes deben elegir un bando: papistas o luteranos.

Erasmo es el único neutral al sentirse partícipe de ambas fracciones: defiende la doctrina evangélica por ser el primero en apoyarla por convicción, y a la iglesia católica pues representa para él la defensa de la última forma de unión espiritual en un mundo en crisis. No logra apaciguar los fuegos fanáticos.

Cuando ningún partido lo puede convencer de unirse, cambian de táctica: ahora lo denigran y difaman; Lutero pronuncia una maldición, la iglesia católica pone sus libros en el index. Pero las amenazas y los insultos no cambian la actitud de este pensador libre, nulli concedo y homo per se son sus principios. No se sacrificó por sus ideas, trató de evitar la exposición directa; en este periodo de locura conservó su tesoro espiritual, su confianza en la humanidad. Todas las pasiones se cansan, el fanatismo se supera. La razón puede esperar y resistir.

\section{Castello contra Calvino}

Calvino radicó en Ginebra y fundó su propia reforma religiosa, comenzando como Lutero con la traducción de la Biblia, esta vez en francés. En su juventud visitó el mismo colegio de Montaigne, Erasmo y Loyola. Con 26 años, ya tenía su visión de mundo, basada en una lógica y resolución implacables. Nunca cambió la más mínima parte de su visión y para él la humanidad fue sobre todo pecadora.

Para acercarse a Dios, todos deben obedecer y subordinarse, sin pensamiento propio y sin crítica, a la palabra del predicador como administrador y mensajero de la palabra de Dios. La Biblia es la única guía para la moral, pensamiento, credo, jurisprudencia y vida. Esta dictadura dogmática, nacida de un movimiento para la libertad, se convirtió en un poder más riguroso y cruel contra la libertad que el poder anterior de la iglesia católica.

Calvino mismo fue un asceta riguroso y un misántropo sin compasión. Destruyó todos los ornamentos, no permitió fiestas ni celebraciones: a la figura de Dios no se le celebra ni se le ama, solamente se le teme. 
Durante la peste (1542-1545), Castello fue rector de la escuela y el único en visitar a los enfermos. Los otros predicadores mantenían su distancia de las víctimas. Su gran plan fue la traducción de la Biblia de nuevo al latín y después al francés. Calvino se lo permitió, pero pretendió revisar la obra. Después de haberla leído, Calvino le negó la posición de predicador, por unos dos puntos insignificantes de discordia en el texto traducido. Castello se vio obligado a dejar Ginebra, se mudó a Basilea y trabajó como corrector en una imprenta y después como lector de griego en la universidad. En su tiempo libre, escribió muchos comentarios y polémicas en defensa de la libertad de las convicciones propias.

Castello se guardó de entrar en confrontación directa con Calvino, hasta que apareció en el escenario Miguel Servet, un aventurero quijotesco, quien declaró el Concilio de Nicea como inválido y el dogma de las tres hipostasis como irreconciliable con la unidad del ser divino. Desapareció en Lyon, París y al final, fue médico personal del arzobispo en Viena. Escribió a Calvino para convencerle de su versión y trabajó en la imprenta de Christianismi Restitutio. Calvino estuvo al tanto de esta obra y envió indirectamente una denuncia a la Inquisición. Al final, los inquisidores no podían evitar capturar a Servet, pero no quisieron hacerle el favor a Calvino de condenarlo, así que pudo escapar.

Servet se dirigió a Ginebra, con la firme convicción de que bajo la protección de Calvino estaría a salvo. Calvino ordenó apresarlo en la iglesia, contrario a las costumbres ejecutadas a los extranjeros; Servet fue torturado en la galera y Calvino con sus intrigas logró efectuar su condena: la quema a cuerpo vivo.

Castello entonces colocó la ofensiva con su Contra libellum Calvini: "Quemar a una persona no significa defender una doctrina, sino matar a una persona". También le repitió lo que él mismo pronunció cuando era perseguido: "No es cristiano perseguir a los excomulgados con armas y quitarles sus derechos humanos". Castello defiende la libertad de pensamiento como derecho sacro y la idea de la tolerancia en Europa.

¿Quién es pues el hereje? La verdad sobre la religión es un misterio y ocasiona todavía guerras sangrientas, hasta que las mentes y las almas no se iluminen con el amor. Todos los que no coincidan con la opinión oficial son considerados herejes.

\section{Kurt Tucholsky}

Kurt Tucholsky, quien nació en Berlín en 1890, hijo de un banquero judío, fue un periodista y escritor muy conocido en el periodo de la República de Weimar (1918-1933). Escribió una novela, Schloss Gripsholm, y muchos cuentos, artículos, aforismos y diálogos en estilo divertido y al mismo tiempo crítico. Durante la Primera Guerra Mundial tuvo que participar en Polonia y más tarde en Rumanía, pero pronto pudo redactar la revista del frente y trató de evitar ambos factores de la guerra: ser matado y asesinar. A su regreso en Berlín (1918), se pronunció antimilitarista y pacifista; una de sus expresiones fue: "Soldados son asesinos". A partir del 1924 pasó la mayor parte de su vida en el exterior, primero en París 
y después en Suecia. En 1933, Hitler ordenó la quema de sus libros y le quitó la nacionalidad. En 1935, se suicidó en Goteborg, Suecia.

Como Zweig, él también amó y respetó mucho Francia y a los franceses. Según lo manifestado en su curriculum vitae de 1934, el cual elaboró para obtener la nacionalidad sueca, desde antes de la guerra él trabajaba para la paz, especialmente entre los enemigos de siempre: Francia y Alemania. En su primera obra, Rheinsberg: Ein Bilderbuch für Verliebte (1912) (Rheinsberg: un libro ilustrado para enamorados), cuando los dos enamorados se maravillan de la belleza de la Heimat (tierra natal), Claire pregunta si Wolfgang está dispuesto a morir por la patria y él le contesta que sí está dispuesto a morir por ella, pero no por la patria.

En el artículo Macchiavelli (Die Weltbühne, 1918), condena cómo a partir del 1 agosto de 1914, cuando Alemania entró en guerra con Inglaterra, se mezcló la política de poder y agresión con la ética. La política no tiene nada en común con la ética y en este caso específico sirvió, como siempre, para justificar el envío al frente de batala de millones de hombres para aniquilar o ser aniquilados. ¿Acaso el príncipe tenía el derecho divino de declarar la guerra contra un pueblo?

En Grimms Märchen (1928) (Cuento de Grimm), comenta el libro de un cierto Hans Grimm, quien llora por la pérdida de la colonia en África llamada DeutschSüdwest-Afrika. En el Tratado de Versalles, Alemania renunció a sus dos colonias en África y Grimm considera este acto como una injusticia que Alemania tuvo que firmar. Sostiene que esta nación necesita colonias; Tucholsky, por su parte, observa que Alemania no las necesita, que las colonias son un anacronismo.

Grimm, a su vez, lamenta que ahora bajo el mandato de África del Sur, los alemanes no son considerados amigables. Tucholsky menciona que fueron los alemanes quienes invadieron sin ninguna razón un país pacífico como Bélgica y que la agresión es siempre agresión, independientemente de donde provenga. El Tratado de Versalles también es un acto de agresión, pero para no tener que sufrir dichas injusticias, no hay que comenzar las guerras.

\section{Der bewachte Kriegsschauplatz (1931) (El campo de batalla vigilado) "Soldaten sind Mörder"}

En este relato ocurre que detrás de las trincheras donde se disparan los obreros y los empleados, mientras sus jefes ganan bien con esta actividad en la comodidad de sus casas, montan a caballo los sargentos mayores. Ellos no se encuentran al frente, solo por detrás se hacen grandes, supuestamente para evitar que un civil se mezcle en la pelea . Pero también vigilan la parte delantera, para que no se mezcle con su tropa un soldado perdido de otra tropa. Lo que vigilan realmente es que en la parte de enfrente se muera como se debe. Para la mayoría este control es innecesario, ni siquiera conocen cómo llegar a la retaguardia. Y si alguien llega a la parte trasera es capturado y llevado preso ante un tribunal de guerra, y luego a prisión.

Por cuatro años hubo millas cuadradas donde el asesinato fue obligatorio, en cambio, a media hora de distancia fue severamente prohibido. Los soldados 
son asesinos. Los estudiantes que protestan contra esta sentencia deberían leer la exhortación Allorché fummo chiamati del 28 de julio de 1915, de Benedicto XV, donde él llama la guerra una "orrenda carneficina".

Los sargentos de todos los países disparan sobre los desertores, matando así a los que rechazan matar. Y sin embargo, cierran el campo de batalla, argumentando la existencia del orden, la tranquilidad y la civilización de los estados cristianos.

\section{Schloss Gripsholm (Castillo Gripsholm)}

Esta novela es la obra más conocida de Tucholsky, un relato veraniego divertido e irónico, que se vuelve progresivamente más serio y acusatorio. Como antecedentes a este relato, cabe mencionar que durante la Gran Guerra, cuando ya no había comida ni vestimenta en Alemania, debido al bloqueo marino inglés y a la falta de peones, animales de carga y abono para la agricultura, se debió tener consideraciones especiales hacia los niños, pues en lo concerniente a la alimentación, Alemania ya había perdido la guerra en 1916.

En verano, algunos niños fueron enviados a Suecia, país neutral en esta guerra, para que fueran albergados en casas de familias donde pudieran comer y recuperarse. Las familias alemanas también enviaron a sus hijos a colonias de vacaciones durante el verano, estas se ubicaban sobre todo en el norte, a la orilla del mar, o en Suecia. De esta manera, no tenían que interrumpir sus trabajos y solucionaban el problema del cuido de los niños.

La novela se compone de dos partes: por un lado, una pareja de enamorados, Peter y Lydia, toma vacaciones de cinco semanas en verano y viaja a Suecia. Se instalan en una linda casita al borde de un lago en Mariefred, en el anexo nuevo de un castillo antiguo llamado Gripsholm. Debido a que pasan sus vacaciones junto a sus visitas, resulta una lectura muy amena, gracias al lenguaje que se utiliza y los espacios descritos.

Por otro lado, está Ada, una niña de nueve años, quien se encuentra alojada en una colonia para niñas al otro lado del lago, su historia se desarrolla paralela a la de la pareja y se llega a unir; este análisis se centrará en la vivencia de Ada.

Ada vive en una colonia junto a cuarenta niñas, la gran mayoría alemanas, bajo la tutela de una mujer alemana sádica y autoritaria. Como castigo principal, además del abuso verbal y de empujones violentos, ocurre el robo de alimentos y la no participación en los paseos al aire libre. En general, todas están atemorizadas, pero Ada en especial se siente muy sola y aislada, no tiene amigas.

Un lindo día la pareja está disfrutando del bosque y del prado y ve pasar una fila de niñas, como perlitas en un cordel, caminando de dos en dos. En la punta, camina una persona dominante, mirando de vez en cuando para atrás. Nadie habla. El grupo pasa a la pareja y al final, está una niña sola, con sus ojos ya vacíos de lágrimas. Lydia, la mujer de la pareja, le da rápidamente dos florcitas recogidas en el momento. Ante la mirada de la "mujer terror", acelera sus pasos. 
En la próxima escena la niña está en la cama y piensa sobre el padre que la abandonó y recuerda los momentos hermosos; piensa en su madre, tan lejos en Suiza, a quien le había escrito tres cartas implorándole que la sacaran de ese sitio; una sirvienta las había llevado al correo, hasta que la "mujer terror" conocida como Teufelsbraten (asado del diablo - por ser este el término con el que se dirigía a las niñas cuando se enojaba) descubrió lo que sucedía. Despidió a la sirvienta y jaló del pelo a la niña y desde ese momento, todas las cartas a la madre solo dicen cosas positivas.

Piensa la niña que a lo mejor la madre no tiene dinero para tenerla consigo. En ese lugar se siente tan sola y llena de miedo que no puede dormir. A ese mismo lugar vinieron ella, su madre y su hermanito ya hace años; su hermano murió después de cuatro días de haber llegado, supuestamente de una gripe. Ella va al cementerio de vez en cuando. Mañana es día de bañarse en el lago. Bajo la almohada sus deditos encuentran las dos florcitas de campo ya marchitas que le dio Lydia.

Otro día, la señora directora encuentra el armario abierto de una niña, grita, controla, encuentra alimentos escondidos entre la ropa, y monta en cólera. Llama a todas a la sala comedor, trae a la niña acusada, dice que si una de ellas falla, todas deben sufrir el castigo. La culpable no come en esa noche, no puede salir a pasear por ocho días y al día siguiente la comida es de solo media porción. Para ninguna hay baño en el lago hoy y deben hacer ejercicios de escritura. Todas van a sus dormitorios, son ocho niñas por cuarto. La señora Adriani queda sola en el comedor. Está furiosa, lo único que puede calmarla es la visión de su acto apenas cumplido. Tuvo un público muy atento. Todo en la casa está bajo su control y por eso no le gusta salir a pasear con las niñas, la naturaleza no está bajo sus órdenes. Este es su reino soberano, ella moldea a las chicas, a las sirvientas, a sus sobrinas -su marido no cuenta-. Con tantas figuras puede entablar un juego doloroso. Siempre gana ella, puede trabajar como una mula y sus emociones quedan reservadas para ella misma.

Mientras tanto, la pareja está cerca de la casa de la colonia, reposando sobre el musgo. Súbitamente, se abre una puerta lateral y sale una niñita. Corre como un animal cazado, sin saber el rumbo y llega justo donde la pareja. Llora sin parar como para romper corazones. Cuenta que está castigada por el robo de la compañera y que no le dan de comer, le van a pegar y quiere ir donde su mamá. Se llama Ada Collin y su madre está en Zurich. Cuando le preguntan por la dirección, llega la "mujer diablo", recoge a la niña y dice a la pareja que no debe mezclarse en asuntos ajenos, que ella tiene la autorización de los padres de cuidar a las niñas. Lydia, también llamada princesa por su pareja, se baja y limpia la carita de la niña. Así puede susurrarle que deje un papelito fuera de alguna puerta con la dirección de la madre.

La "dragona" se lleva a la niña como si fuera una cosa. Después de media hora, la princesa encuentra el papelito en el zacate con la dirección completa de la madre. Deciden escribirle una carta, donde describen lo que han visto, que no quieren inmiscuirse en la política familiar, pero que no debe dirigirse a la "mujer dragona", que esté tranquila porque ellos van a pensar en lo que se puede hacer, pero que quieren hablarle por teléfono. 
La madre contesta que estaría muy agradecida si se fueran a hablar con la señora Adriani y la llamaran después. El hombre no se siente bien con la idea de afrontar a esta mujer mala y desconocida, pero cuando le viene a la mente su sargento mayor durante la guerra y la niña golpeada llorando, está dispuesto a entrar en acción. Antes de ir, compran una muñeca para la niña. Llegan a la casa, donde se les dice que la señora en este momento está controlando las pertenencias de las niñas. Esta baja de la escalera y los saluda, y cuando le confirman que tienen la carta de la madre autorizándolos para ver por la niña, los deja entrar en el comedor. Le dicen que la madre no puede llegar este verano a Suecia y que le gustaría que alguien viera a su niña. La señora Adriani contesta que es ella quien se ocupa de la niña. No está muy de acuerdo con la solicitud de los foráneos de ver a la niña para hablarle y darle un mensaje de la madre. Ellos le responden que no es que pidan ver a la niña sola, sino siempre bajo su supervisión. La directora indica que encuentra este comportamiento muy raro, que teme esta intromisión en sus métodos educativos, la princesa busca tranquilizarla diciéndole que la idea no es controlarla ni causar disturbios en su trabajo, que seguramente tiene mucho que hacer con los niños.

Llega la niña con mucho temor, casi no se escucha su saludo. La princesa le dice que la mamá le envía saludos y que pregunta en la carta si el sepulcro de Will, su hermano pequeño, está en buen estado. La niña no puede contestar, la señora confirma que el sepulcro está en buen estado, que van a visitarlo cada dos semanas y que ella se ocupa de su cuidado. Entonces la princesa le entrega la muñeca a Ada, diciéndole que puede jugar a las muñecas con las otras chicas. La niña recoge la muñeca, sus ojos se llenan de llanto, mientras la directora le ordena salir. Pero la princesa antes de que se vaya le informa que puede dar cualquier información para su madre a ellos que viven en el Schloss Gripsholm.

La directora manifiesta que no hay nada que informar, que todo pasa por ella. Después de alejar a la niña con unos gritos, vuelve y manda a los visitantes fuera, que no vuelvan a acercarse a su propiedad de nuevo, que llamará a la policía. Cuando pide ver la carta, los visitantes se van despacio a la puerta y salen sin decir nada. Quien amenaza muestra su debilidad. La "mujer dragona" se deja ir con gritos descontrolados.

Por teléfono comunican a la madre la situación de la niña, que no puede quedarse con esta educadora imposible, que la quieren recoger. Ella debe enviarle una carta a la directora, en la que los autoriza a recoger a su hija de este hogar, junto con un cheque para saldar la cuenta. El hombre tiene compromisos en Suiza y él le llevaría a su hija.

Pasan los días y la carta no llega. Las vacaciones están por terminarse. Los dos se preguntan que habrá pasado, por qué la mujer no hace lo que habían pactado, por qué no confía en ellos pero en cambio sí confió en la "mujer dragón”. Cuando vuelven a la casa, encuentran la carta y planean ir después del almuerzo a la casa de la colonia. Pero mientras comen llega la niña, llorando y les cuenta que la "dragona" la maltrató tanto que tuvo que escapar. Vuelven a la casa juntos, después de asegurarle a Ada que no la van a dejar allí. La dragona ahora con voz amable le dice a la niña que se esconda detrás de la princesa, que 
no tiene razón de escapar, que no debe tener miedo de ella, que se va con gente desconocida y que ni siquiera están casados. El hombre le pregunta por qué se fue, qué causó este escape. A la pregunta de qué piensa hacer ahora con la niña, les contesta que la va a castigar, con una mirada alegre y hambrienta al mismo tiempo. Pero cuando le dicen que la chica no se quedaría, que solamente quieren recoger sus pertenencias y saldar la cuenta, la "dragona" llora sin lágrimas y se lamenta de su vida, de su esposo enfermo, de su rol de madre en este hogar, hasta que le sale una mala palabra.

En cierto punto, el hombre piensa reconocer la insatisfacción sexual de esta mujer, pero además existe el instinto primario del ser humano: ambición de poder y más poder. A la entrega del cheque ella debe dar un recibo y ellos se marchan con la niña; pero lamentablemente, quedan en poder de ella las otras niñas.

El narrador, en cierto punto, observa cómo la directora jala a la pequeña víctima, entonces tiene una visión de un anfiteatro romano con los gladiadores y las bestias, la lucha y el público gozando de este espectáculo violento.

De igual manera, en la actualidad la agresión prevalece, las películas, los videojuegos y otros productos culturales rinden tributo a la violencia, sin tomar en cuenta lo que pasa en el resto del mundo.

Esta novela nos muestra otra arista de la guerra: los niños no se salvan de la violencia, pues esta no se limita al campo de batalla, sino que avanza en todas direcciones. Los agresores no se mantienen en un prototipo sino que, como en este caso, pueden ser amas de casa.

\section{Conclusión}

Zweig y Tucholsky tenían más o menos los mismos antecedentes; sin embargo, las coordenadas sociohistóricas de sus países los diferencian. Berlín y Viena constituyeron dos mundos completamente opuestos: Viena era una ciudad antigua, desde tiempos inmemorables la capital de un impero multicultural, la gente vivía con un espíritu de humanidad, tolerancia y tranquilidad, "vivre et laisser vivre".

Berlín, por el contrario, solamente a finales del siglo XIX obtuvo importancia en el mundo debido a las batallas ganadas por el ejército prusiano/alemán. El ambiente fue estructurado en jerarquías, la vida ordenada hasta en cada pequeño detalle, como lo describió Heinrich Mann (el hermano mayor de Thomas Mann) en su novela Der Untertan (El súbdito). El autor logra representar el cambio de la sociedad alemana del liberalismo del siglo anterior a la mentalidad que adora al Kaiser y pisa a toda persona socialmente inferior. Con esta mentalidad, se inició la Gran Guerra, pensando que iba a durar máximo un año; sin embargo, tuvo como producto directo el nazismo.

Zweig usa un lenguaje suave, colorido, reflexivo, expresa su disconformidad con delicadeza. Su estilo es elaborado, aunque piensa que escribe de manera concisa. Para el gusto actual se podría pensar que sus escritos son muy extensos y sus obras voluminosas. 
Tucholsky, por su parte, posee un estilo directo, es ofensivo, polémico, repetidamente juzga al pueblo alemán como estúpido, torpe, cobarde, en las obras donde lucha contra este tipo de persona. Su lenguaje es breve y plurisemántico.

Los dos autores son dignos representantes de una minoría que estaba consciente de lo que sucedía y no lo aceptó, y por eso trató de frenar o cambiar el desarrollo de la historia. Hoy en día, Tucholsky es muy apreciado en Alemania; sin embargo, la población que él despreció tanto no está extinta, aún quedan resabios de ignorancia y soberbia. Como dato curioso encontramos que muchos dichos usados regularmente en Alemania fueron creados por él.

Estos son solamente dos representantes de un vasto grupo de humanistas, que no contemplaban ni querían una guerra. Sobra decir que hoy, en el siglo XXI, en nuestra sociedad globalizada, persisten la intolerancia y la guerra, el fanatismo y la agresión, la incomprensión y la egolatría.

\section{Bibliografía}

Holdack, N. (2013). Es muss einer den Frieden beginnen - Jahrhundertautoren gegen den Krieg. Berlin: Aufbau Digital, Aufbau Verlag.

Lagarde \& Michard (1973). XXe Siècle. Paris/Bruxelles/Montréal: Bordas.

Papa Benedicto XV, Exhortatio "Allorché fummo chiamati", Vaticano, 8 de julio de 1915, www.vatican.va/holy_father/benedict_xv/apost_exhortations/

Schön, K. (2014). Kurt Tucholskys Kritik an den Deutschen. München: BookRix.

Tucholsky, K. (2012). Kurt Tucholsky: Ausgewählte Werke und Schriften. eClassica-AuraBooks.

Tucholsky, K. (2012). Wenn einer eine Reise tut .... Altenmünster: Erweiterte Ausgabe, Jazzybee Verlag Jürgen Beck.

Zweig, S. (2013). Stefan Zweig - Gesammelte Werke. Deutschland: Null Papier Verlag. 
